\title{
Elastic-plastic finite element analysis of plates
}

\section{A. W. WEGMULLER}

\section{Dr M. A. Crisfield, Transport and Road Research Laboratory}

The layered finite element model adopted by the Author leads to an accurate representation of the spread of plasticity through the depth of the plate. I initially adopted a similar method for the large deflexion elastic-plastic analysis of plates. ${ }^{12}$ However, the layered solution was found to be prohibitively uneconomic and consequently $I$ used an approximate yield criterion ${ }^{13}$ which is a direct function of the stress resultants. In the current case of small deflexion bending analysis, this yield criterion becomes

$$
M_{x}{ }^{2}+M_{y}{ }^{2}-M_{x} M_{y}+3 M_{x y}{ }^{2}=M_{\mathrm{p}}{ }^{2} \text {. . . . . }
$$

which is the sandwich plate approximation adopted by Lopez and Ang. ${ }^{3}$ I have recently adapted Ilyushin' ${ }^{13}$ yield criterion to take account of intermediate plasticity. ${ }^{14,15}$ For small deflexion bending problems, the modified yield criterion degenerates to a sandwich model in which the skins of the analogous sandwich plate are given hardening properties such that the resulting equivalent moment/equivalent plastic curvature relationship follows closely the uniaxial moment/curvature curve, i.e.

$$
M_{x}^{2}+M_{y}^{2}-M_{x} M_{y}+3 M_{x y}^{2}=M_{0}^{2}
$$

where

$$
M_{\mathrm{e}}=M_{\mathrm{p}}\left[1-\frac{1}{3} \exp \left(-\frac{4 E h}{3 \sigma_{y}} \sum \Delta_{\chi_{\mathrm{ps}}}\right)\right]
$$

and the equivalent plastic curvature increment is given by

$$
\Delta \chi_{\mathrm{ps}}{ }^{2}=\frac{4}{3}\left(\Delta \chi_{\mathrm{px}}{ }^{2}+\Delta \chi_{\mathrm{p} y}{ }^{2}+\Delta \chi_{\mathrm{p} x} \Delta \chi_{\mathrm{p} y}+\Delta \chi_{\mathrm{p}_{x y}}^{2} / 4\right) \quad \text {. . . . }
$$

A similar approach was used for the elastic-plastic analysis of reinforced slabs by Yam and Das. ${ }^{18}$

18. I have analysed the clamped plate shown in Fig. 3 using the Author's coarse $8 \times 8$ mesh. The results are shown in Fig. 6 in which the non-dimensional ratios are at first sight different from those of the Author. However, there appears to be a mistake in Fig. 3 so that the load axis ratio in Fig. 6 is in fact the same as the Author's. It would not be possible to show single upper and lower bounds if the non-dimensional ratio really was $P / P_{y}$ because this implies different scales for the different meshes. The undefined $P_{y}$ is assumed to be the load at which an element layer first yields.

19. The computed load/central deflexion curve lies very close to the layered finite element solution. However, the computed maximum load $\left(2 \cdot 02 q L^{2} / 24 M_{\mathrm{p}}\right)$ is below Hodge's ${ }^{1}$ upper bound. This greater accuracy is probably due to the more sophisticated method that is used to deal with the spread of plasticity in the plane of the plate. 


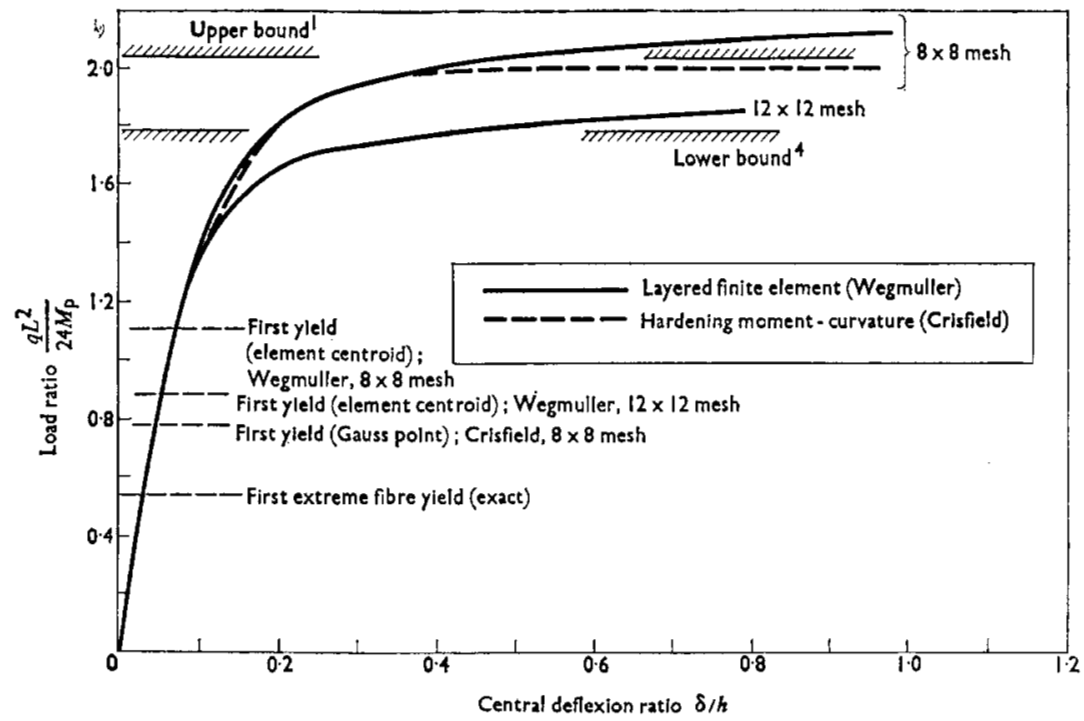

Fig. 6. Load plotted against deflexion for clamped square plate subject to uniformly distributed load $q$

Whereas the Author assumes the whole element layer to be either elastic or plastic, I allow for the spread of plasticity within the plane of the element by monitoring plasticity at the four $2 \times 2$ Gauss integration stations. ${ }^{17}$ If a subdivision through the depth is adopted, it is probably more accurate to use Simpson's rule ${ }^{18}$ or Gaussian quadrature $^{12}$ than the Author's direct layered approach.

\section{Professor Wegmuller}

As pointed out by $\mathrm{Dr}$ Crisfield, the incremental constitutive relations can be expressed in terms of stress resultants (moments) rather than stresses, and use can be made of approximate yield conditions. This may well lead to substantial computational advantages.

21. However, if the stress distribution through the thickness of the plate is of interest, then the layered approach is more revealing. As pointed out in the Paper, this approach can easily be extended to include in-plane behaviour. Hence, in-plane displacements occurring at the level of the middle plane of the plate and causing the neutral axis to shift can be studied. ${ }^{11}$ This possibility has played an important role in the redistribution of stresses due to cracking, and it is plausible that it might have an effect on plastification. More research is needed in this area.

22. Dr Crisfield's presentation of the results for the clamped plate discussed is clearly more appropriate than that shown in Fig. 3. As pointed out in the Paper, the results for the coarse $8 \times 8$ mesh are not very accurate because of the high stress gradients occurring in the vicinity of the clamped edges of the plate and because stresses were computed at the centroid of the layers. It can be anticipated that more refined in-plane numerical integration techniques and finer meshes in regions of high stress gradients will significantly improve the accuracy. 
23. Besides the tangent stiffness approach discussed in the Paper, the constant stiffness (initial stress) method and other formulations have been used to predict the inelastic response of plates and shells. However, few studies have been made to compare these different approaches. More research in this area is needed to arrive at valid conclusions.

\section{References}

12. CRISFIELD M. A. Large deflection elasto-plastic buckling analysis of plates using finite elements. Transport and Road Research Laboratory, Crowthorne, 1973, Report LR 593.

13. Ilyushin A. A. Plasticité. Editions Eyrolles, Paris, 1956.

14. CRISFIELD M. A. On an approximate yield criterion for thin steel shells. Transport and Road Research Laboratory, Crowthorne, 1974, Report LR 658.

15. YAM L. C. P. Problem classification and basic techniques in analysis of inelastic stability of plates. Transport and Road Research Laboratory, Crowthorne, 1974, Report LR 657.

16. YAM L. C. P. and DAs P. C. Elastoplastic analysis of reinforced concrete slabs-Some implications of limit state design. Proc. Int. Conf. Dev. Bridge Des. and Constr., Cardiff. K. C. Rockey et al. (eds). Crosby Lockwood, London, 1971, 144-160.

17. CRISFIELD A. M. Some approximations in the non-linear analysis of rectangular plates using finite elements. Transport and Road Research Laboratory, Crowthorne, 1974, Report SR. 51 UC.

18. Stricklin J. A. et al. Computation and solution procedures for non-linear analysis by combined finite element-finite difference methods. Comput. Struct., 1972, 2, Dec., 955-974. 